\title{
Investigation of adsorption mechanism of phosphate(V) ions on the nanostructured Na-A zeolite surface modified with ionic polyacrylamide with regard to their removal from aqueous solution
}

\author{
Małgorzata Wiśniewska ${ }^{1}$. Teresa Urban ${ }^{1}$ - Stanisław Chibowski ${ }^{1}$. Gracja Fijałkowska ${ }^{1}$. Magdalena Medykowska ${ }^{1}$. \\ Agnieszka Nosal-Wiercińska ${ }^{2} \cdot$ Wojciech Franus ${ }^{3} \cdot$ Rafał Panek $^{3} \cdot$ Katarzyna Szewczuk-Karpisz $^{4}$
}

Received: 15 October 2019 / Accepted: 6 April 2020 / Published online: 18 April 2020

(c) The Author(s) 2020

\begin{abstract}
The sorption properties of Na-A-type synthetic zeolite, obtained from fly ash with regard to the phosphate(V) ions, were determined. The Na-A zeolite was prepared using hydrothermal conversion of fly ash with aqueous sodium hydroxide. The effects of solution $\mathrm{pH}$ and zeolite surface modification by ionic polyacrylamide (PAM) were examined. Both anionic and cationic forms of PAM were applied. The adsorption and electrokinetic data were obtained by means of spectrophotometric measurements, potentiometric titrations and zeta potential determination. It was shown that the presence of ionic polyacrylamide adsorption layers modifies the surface properties of the solid. The resulting composite material (zeolite/polymer) can be applied for effective removal of phosphate(V) ions from the liquid medium. Its regeneration possibilities are also considerable. Additionally, the use of fly ash for zeolite preparation leads to management of hazardous waste material.
\end{abstract}

Keywords Nanostructured Na-A synthetic zeolite $\cdot$ Fly ash management $\cdot$ Phosphate(v) ions removal $\cdot$ Ionic polyacrylamide layer $\cdot$ Electrokinetic properties $\cdot$ Solid surface modification

\section{Introduction}

The adsorption process has found numerous applications in many industries, mainly in technologies used in environmental protection. This includes, among others, the removal of undesirable organic and inorganic substances present in sewages (Holan and Volesky 1994; Wawrzkiewicz et al. 2015;

Małgorzata Wiśniewska

wisniewska@hektor.umcs.lublin.pl

1 Department of Radiochemistry and Environmental Chemistry, Institute of Chemical Sciences, Faculty of Chemistry, Maria Curie- Sklodowska University, M. Curie-Sklodowska Sq. 3, 20-031 Lublin, Poland

2 Department of Analytical Chemistry, Institute of Chemical Sciences, Faculty of Chemistry, Maria Curie- Sklodowska University, M. Curie-Sklodowska Sq. 3, 20-031 Lublin, Poland

3 Department of Geotechnics, Civil Engineering and Architecture Faculty, Lublin University of Technology, Nadbystrzycka Street 40, 20-618 Lublin, Poland

4 Institute of Agrophysics, Polish Academy of Sciences, Doświadczalna 4, 20-290 Lublin, Poland
Wiśniewska et al. 2017; Bazan-Wozniak et al. 2017; Goncharuk et al. 2019). One of the applications of the adsorption process is separation of phosphate ions from wastewaters. They are destructive from the environment and contribute to the formation of surface water eutrophication (Yang et al. 2008).

The source of phosphorus in the aquatic environment is the organic compounds that are formed as a result of the decomposition of organic substances, both of animal and plant origin. These are, for example, fructose-6-phosphate, glucose-6-phosphate or phospholipids. Another reason for the presence of phosphorus in the waters is the arable fields enriched with fertilizers containing phosphates as well as all plant protection products such as organophosphate pesticides. Nevertheless, municipal wastewaters (domestic detergents, food additives, personal care products) are considered to be one of the main reasons for phosphorus presence in the aquatic environment (Selman and Greenhalgh 2010).

More and more effective materials for adsorption of harmful and toxic impurities have been sought for many years. Important criteria are their price as well as the method of their synthesis. Recently, zeolites have become an important group of adsorbents. Due to the presence of 
many channels and spaces in their structure, they are characterized by a large specific surface area. As a result, they have the ability to adsorb not only heavy metal ions but also other substances that are widely recognized as harmful. On the other hand, well-developed methods of their synthesis control the increasing usage of these solids. One of them is an environmental friendly procedure in which the starting material is a by-product of coal combustion, namely fly ash (Franus et al. 2014; Bukhari et al. 2015; Bandura et al. 2016, 2017). Within 1 year, large amounts of this waste substance are produced, resulting in a destructive impact on the environment. This waste material that is toxic and useless is processed into a non-toxic product that can be reused. The application of fly ash for the synthesis of zeolites is possible owing to the content of aluminosilicate glaze-i.e., elements such as silicon and aluminum, which are necessary for the construction of zeolitic structure. It is mainly formed by silicon, aluminum, oxygen and metals (especially zinc and titanium) atoms. The $\mathrm{Si}$ and $\mathrm{Al}$ atoms are tetrahedrally coordinated with each other through the oxygen atoms. In this way, the interlinked tetrahedrons of alumina $\left(\mathrm{AlO}_{4}\right)$ and silica $\left(\mathrm{SiO}_{4}\right)$ create the three dimensional network of interconnected pores and tunnels of different sizes in which the so-called "zeolite water" is collected.

Phosphorus elimination is a very difficult process and not always fully effective. Removal of organic phosphorus from wastewaters can be accomplished as a result of destruction in the course of chemical oxidation, chemical precipitation combined with a coagulation process or anaerobic biodegradation of compounds of organic origin containing phosphorus (Bashan et al. 2004; Li et al. 2009; Yang et al. 2010). The methods of biological phosphorus removal from wastewaters are based on the use of specific activated sludge bacteria (the so-called phosphorus bacteria). They are able to accumulate phosphorus in the form of polyphosphates in larger amounts in relation to their metabolic needs. Another way to remove phosphorus from a liquid medium is to use effective adsorbents (Bouzid et al. 2008; Liu et al. 2008; Jiang et al. 2013; Al-Zboon 2018).

Thus, this paper focuses on application of Na-A synthetic zeolite obtained from fly ash for removal of phosphate $(\mathrm{V})$ ions from aqueous solution by their adsorption at the solid-liquid interface. The effects of zeolite surface modification by ionic polyacrylamide-PAM (both anionic and cationic forms) are examined. PAM is a non-toxic linear polymer well soluble in water which is characterized by good biodegradability and biocompatibility (Wiśniewska 2018). Due to the fact that the solution $\mathrm{pH}$ influences significantly the structure of adsorption layer of ionic polyacrylamide, the spectrophotometric and electrokinetic measurements were performed in the $\mathrm{pH}$ range $3-10$. Determination of the most likely mechanism of interactions in the zeolite-PAM-phosphate $(\mathrm{V})$ ions suspension allowed the selection of the most effective systems for removing of undesirable inorganic anions from the aqueous phase.

\section{Experimental}

\section{Materials and their characteristics}

The Na-A synthetic zeolite was prepared on a quarter-technical scale using a prototype installation for the synthesis of zeolites from fly ash located at the Lublin University of Technology. The applied adsorbent was obtained by the hydrothermal conversion of fly ash with aqueous sodium hydroxide according to the following reaction:

Fly ash $+\mathrm{NaOH} \rightarrow \mathrm{Na}-$ A zeolite + ash residue

Fly ash originated from conventional coal combustion. The aluminosilicate glaze present in the fly ash is a carrier of aluminum and silicon (which are necessary for the zeolite structure building); whereas, sodium atoms came from $\mathrm{NaOH}$ which was a Na carrier and dissolved the aluminosilicate phase in fly ash. Control of the reaction parameters such as temperature, time, substrate concentration, aluminosilicate material containing the Na-A zeolite phase and unreacted ash residue (consisting mainly of mullite and quartz) was achieved (Wdowin et al. 2014).

The textural parameters of Na-A zeolite (determined by the BET method, ASAP 2020 analyzer, Micromeritics Instrument Corporation) and its elemental composition (determined using the XRF technique, Panalytical ED-XRF type Epsilon 3 spectrometer) are presented in Table 1. The nitrogen adsorption/desorption isotherms were measured at liquid nitrogen temperature $77 \mathrm{~K}\left(-194.85^{\circ} \mathrm{C}\right)$ in the relative pressure $\mathrm{p} / \mathrm{p}_{0}$ changing in the range from $1.7 \cdot 10^{-7}$ to 0.991. Energy-dispersion X-ray fluorescence experiments were carried out for elements from $\mathrm{Na}$ to Am on an apparatus equipped with an $\mathrm{X}$-ray tube $\mathrm{Rh} 9 \mathrm{~W}$ with energy of $50 \mathrm{kV}$.

The Na-A surface without and in the presence of ionic polyacrylamide was also observed by SEM microscope (Quanta 3D FEG, FEI Company). The surface functional groups of zeolite were identified using the Fourier-transform infrared spectroscopy (FTIR) using the FTIR spectrometer (Nicolet $8700 \mathrm{~A}$, Thermo Scientific). The spectra were recorded in the range of $400-4000 \mathrm{~cm}^{-1}$.

The Na-A zeolite was selected for studies due to the most favorable values of textural parameters (relation of the specific surface area and mean pore diameter) and surface acid-base properties for adsorption of highmolecular-weight ionic polyacrylamide (Wiśniewska et al. 2019). The preliminary studies carried out in the examined mixed systems adsorbates with the use of other 
Table 1 Applied adsorbent and adsorbates characteristics

\begin{tabular}{|c|c|c|c|}
\hline \multicolumn{2}{|l|}{ Adsorbent: Na-A zeolite } & \multicolumn{2}{|l|}{ Adsorbates } \\
\hline Textural parameters & & AN PAM & \\
\hline BET surface area $\left[\mathrm{m}^{2} / \mathrm{g}\right]$ & 74.16 & $\mathrm{pK}_{\mathrm{a}}$ & 3.6 \\
\hline Micropore area $\left[\mathrm{m}^{2} / \mathrm{g}\right]$ & 47.24 & Molecular weight [Da] & $15,500,000$ \\
\hline Pore volume $\left[\mathrm{cm}^{3} / \mathrm{g}\right]$ & 0.136 & Ionic groups content [\%] & 50 \\
\hline Micropore volume $\left[\mathrm{cm}^{3} / \mathrm{g}\right]$ & 0.024 & Dissociation degree [\%] & \\
\hline Mean pore diameter $[\mathrm{nm}]$ & 7.33 & pH 3 & 20.1 \\
\hline Elemental composition [\%] & & pH 6 & 99.6 \\
\hline $\mathrm{Na}_{2} \mathrm{O}$ & 3.225 & $\mathrm{pH} 10$ & 99.9 \\
\hline $\mathrm{MgO}$ & 2.022 & CT PAM & \\
\hline $\mathrm{Al}_{2} \mathrm{O}_{3}$ & 26.234 & $\mathrm{pK}_{\mathrm{b}}$ & 9.9 \\
\hline $\mathrm{SiO}_{2}$ & 51.177 & Molecular weight [Da] & $7,000,000$ \\
\hline $\mathrm{P}_{2} \mathrm{O}_{5}$ & 0.216 & Ionic groups content [\%] & 80 \\
\hline $\mathrm{K}_{2} \mathrm{O}$ & 2.326 & Dissociation degree [\%] & \\
\hline $\mathrm{CaO}$ & 3.812 & pH 3 & 99.9 \\
\hline $\mathrm{TiO}_{2}$ & 1.412 & pH 6 & 99.9 \\
\hline $\mathrm{MnO}$ & 0.105 & $\mathrm{pH} 10$ & 48.2 \\
\hline $\mathrm{Fe}_{2} \mathrm{O}_{3}$ & 8.987 & Phosphate(V) ions & \\
\hline
\end{tabular}

zeolites (i.e., Na-X, Na-P1 or sodalite) indicated that they were much less effective in adsorption process of ionic PAM and phosphate(V) ions.

Two samples of ionic polyacrylamide PAM (Korona JV) - the anionic (AN PAM) and cationic (CT PAM) forms were applied as the adsorbates in the study. They differ from each other in the weight average molecular weight and ionic groups content-15,500,000 Da and 50\% for AN PAM, as well as 7,000,000 Da and 80\% for CT PAM. Besides the nonionic amide groups, the AN PAM contains the carboxyl groups; whereas the CT PAM-the quaternary amine ones. The latter are the source of negative and positive charges in the polymer macromolecules. The $\mathrm{pK}$ values $\left(\mathrm{pK}_{\mathrm{a}}\right.$ for AN PAM and $\mathrm{pK}_{\mathrm{b}}$ for CT PAM) of both polymers were determined by the potentiometric titration method (Minczewski and Marczenko 1985). Next, the degrees of ionic groups dissociation $(\alpha)$ as a function of solution $\mathrm{pH}$ were calculated from the Henderson-Hasselbalch formula (Cygański 1999):

$\alpha[\%]=\frac{100}{1+10^{\left(\mathrm{pK}_{\mathrm{a}}-\mathrm{pH}\right)}}$,

$\alpha[\%]=\frac{100}{1+10^{\left(\mathrm{pH}-\mathrm{pK}_{\mathrm{b}}\right)}}$.

The obtained results are presented in Table 1.

Phosphate(V) ions, whose source was potassium dihydrogen phosphate(V)- $\mathrm{KH}_{2} \mathrm{PO}_{4}$ (Sigma-Aldrich), were also used as an adsorbate.

\section{Methods}

The adsorption measurements were performed at $25^{\circ} \mathrm{C}$ using the static method with the three polymer concentrations $(50,100$ and $200 \mathrm{ppm})$ at the $\mathrm{pH}$ values: 3,6 and $10( \pm 0.1)$ using $0.04 \mathrm{~g}$ of $\mathrm{Na}-\mathrm{A}$ zeolite (for $10 \mathrm{~cm}^{3}$ of the solution). The pHs of examined systems were constantly checked and maintained on the constant level during the adsorption process. The reaction of AN PAM with a hyamine proposed by Crummet and Hummel (1963) was applied. The solution absorbance (results from white color of the solution) was measured after 15 min using the UV-VIS spectrophotometer (Carry 1000; Varian) at $500 \mathrm{~nm}$. In the case of CT PAM, the procedure applying acetate buffer, bromine water, sodium formate and starch in potassium iodide was used (Scoggins and Miller 1975). As a result, the blue complex was formed in the solution. Its absorbance was measured after $5 \mathrm{~min}$ at $585 \mathrm{~nm}$. To determine the phosphate( $\mathrm{V})$ ions concentration, the reaction with ammonum molybdate and tin(II) chloride was carried out (Wachowski and Kirszensztejn 1999). The resulting solutions were colored blue. After $10 \mathrm{~min}$, a spectrophotometric measurement of absorbance was made at the wavelength $690 \mathrm{~nm}$.

Before the adsorption experiments the calibration curves were prepared (linear dependencies of absorbance versus the PAM concentration) for both applied forms of polyacrylamide and phosphate( $\mathrm{V})$ ions. The equilibrium concentration of each adsorbate in the solution was 
determined from the difference in concentrations before and after its adsorption process on the zeolite surface.

The desorption tests were performed in the systems of single and mixed adsorbates at $\mathrm{pH} 6$ at polymer and phosphate(V) ions initial concentrations equal to $100 \mathrm{ppm}$. As desorbing agents $\mathrm{HCl}$ and $\mathrm{NaOH}$ solutions with concentration $0.05 \mathrm{~mol} / \mathrm{dm}^{3}$ were used.

The surface charge density $\left(\sigma_{0}\right)$ and zeta potential $(\zeta)$ as a function of solution $\mathrm{pH}$ (Wiśniewska et al. 2019) were determined at $25^{\circ} \mathrm{C}$ in the following systems:

- Zeolite/water,

- Zeolite/AN PAM/water,

- Zeolite/CT PAM/water,

- Zeolite/phosphate(V) ions/water,

- Zeolite/AN PAM/phosphate(V) ions/water,

- Zeolite/CT PAM/ phosphate(V) ions/water.

The potentiometric titration method was applied for determination of $\sigma_{0}$ value and point of zero charge (pzc) of the examined solid (Janusz 1994). The potentiometric titrations of zeolite suspensions without and with adsorbates (with the concentrations of $100 \mathrm{ppm}$ ) were performed within the $\mathrm{pH}$ range 3-11 in the thermostated Teflon vessel using $0.17 \mathrm{~g}$ of the zeolite (for $50 \mathrm{~cm}^{3}$ of the solution). The measuring set was composed of the following parts: burette Dosimat 665 (Methrom), thermostat RE204 (Lauda), pH-meter 71 (Beckman), computer and printer. The solid surface charge density was calculated with the special program Titr_v3 (authored by W. Janusz).

The electrophoretic mobility $\left(U_{\mathrm{e}}\right)$ of the examined zeolite suspensions was measured in the $\mathrm{pH}$ range $3-11$ in the systems (containing $0.07 \mathrm{~g}$ of the solid for $100 \mathrm{~cm}^{3}$ of the solution) without and with adsorbates (with the concentrations of 100 ppm) using Zetasizer Nano ZS (Malvern Instruments). Electrophoretic mobility of solid particles dispersed in the liquid medium was measured using the dip cell (five repetitions of measurements for each sample). The zeta potential $(\zeta)$ was calculated with the special computer program using the Henry equation (Hunter 1981). The isoelectric point (iep) of Na-A zeolite was also determined.

\section{Results and discussion}

The synthetic Na-A zeolite is a mesoporous material with a pore size of approx. $7.3 \mathrm{~nm}$. It has a developed specific surface area of approx. $74.2 \mathrm{~m}^{2} / \mathrm{g}$ (Table 1). In addition, the analysis of the elemental composition of this aluminosilicate shows that the $\mathrm{SiO}_{2}$ content in its structure is almost $51.2 \%$, $\mathrm{Al}_{2} \mathrm{O}_{3}-26.23 \%$, whereas $\mathrm{Na}_{2} \mathrm{O}-3.22 \%$. Among the other elements, $\mathrm{Fe}_{2} \mathrm{O}_{3}-8.99 \%, \mathrm{MgO}-2.02 \%, \mathrm{TiO}_{2}-1.41 \%$, as well as $\mathrm{CaO}-3.81 \%$ and $\mathrm{K}_{2} \mathrm{O}-2.33 \%$, whose ions neutralize the negative charge of the zeolite network, are most commonly represented. The content of other elements $\left(\mathrm{Cr}_{2} \mathrm{O}_{3}, \mathrm{Co}_{3} \mathrm{O}_{4}, \mathrm{NiO}, \mathrm{CuO}, \mathrm{ZnO}, \mathrm{SrO}, \mathrm{ZrO}_{2}, \mathrm{Ag}_{2} \mathrm{O}, \mathrm{BaO}\right.$, $\mathrm{PbO}, \mathrm{MnO}$ ) is below $0.1 \%$.

The results of FTIR analysis of Na-A zeolite are presented in Fig. 1. The bands observed in the spectrum were as follows:

- $3340 \mathrm{~cm}^{-1}$ ascribed to the stretching of $\mathrm{O}-\mathrm{H}$ groups arranged in hydrogen bonds formation,

- $1648 \mathrm{~cm}^{-1}$-the bending of $\mathrm{H}_{2} \mathrm{O}$ molecules in the zeolite voids,

- $975 \mathrm{~cm}^{-1}$-the anti-symmetric $\mathrm{Si}-\mathrm{O}-\mathrm{Al}$ stretching of $\mathrm{T}-\mathrm{O}$ bonds (where $\mathrm{T}$ is the tetrahedrally bonded $\mathrm{Si}$ or $\mathrm{Al})$,

- $705 \mathrm{~cm}^{-1}$-the symmetric T-O-T stretching,

- $545 \mathrm{~cm}^{-1}$ - the symmetric T-O-T stretching of double six membered rings,

- $450 \mathrm{~cm}^{-1}$ - the symmetric $\mathrm{T}-\mathrm{O}$ bending (Zainal Abidin et al. 2017).

Analogous bands were also noted by other researchers (Ng et al. 2009; Abu-Zied 2011).

The adsorption affinity of the adsorbates with ionic character depends largely on the electrostatic conditions in the system, i.e., the sign and density of zeolite surface charge $\left(\sigma_{0}\right)$. Figure 2 shows the changes in the values of this parameter as a function of the solution $\mathrm{pH}$ for the Na-A samples dispersed in water and aqueous solutions of AN PAM, CT PAM, phosphate $(\mathrm{V})$ ions, as well as mixed solutions of both adsorbates, i.e., AN PAM + phosphate $(\mathrm{V})$ ions and CT $\mathrm{PAM}+$ phosphate $(\mathrm{V})$ ions. The analysis of these curves indicated that the point of zero charge (pzc) of synthetic aluminosilicate is at $\mathrm{pH}$ of about 10 (Wiśniewska et al. 2019). This means that in a solution of $\mathrm{pH} 10$, the zeolite has the surface charge equal to zero (the concentrations of the positively and negatively charged surface groups are the same). Thus, at $\mathrm{pH}$

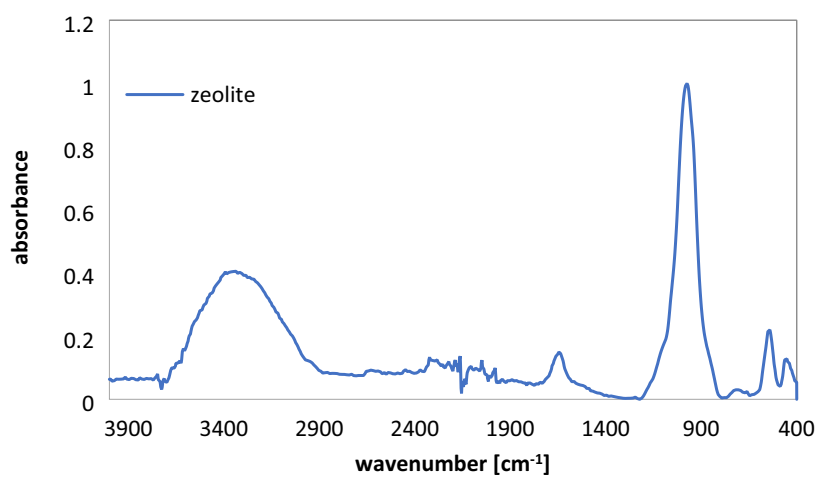

Fig. 1 FTIR spectrum of Na-A zeolite 

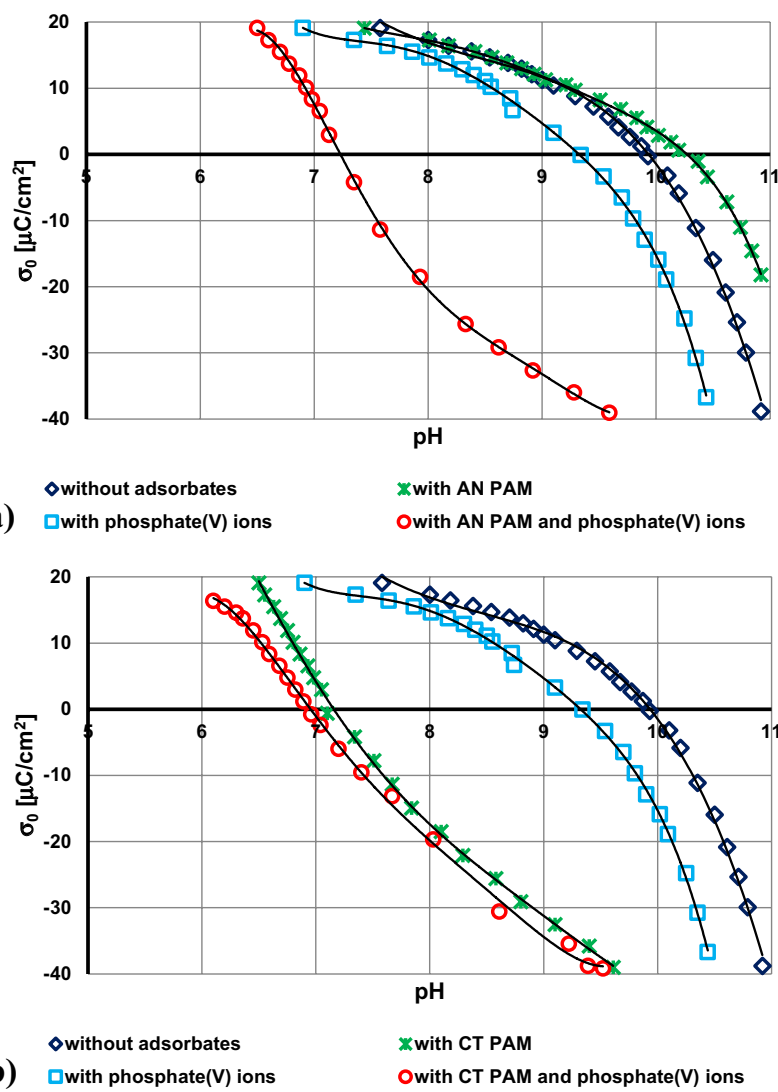

Fig. 2 Surface charge density of Na-A zeolite without and with adsorbed PAM or/and phosphate(V) ions: a AN PAM, b CT PAM

3 and 6, at which adsorption measurements were also made, the surface charge of the solid assumes positive values.

The presence of phosphate $(\mathrm{V})$ ions in the system causes a decrease in the zeolite surface charge density as well as the shift of the $\mathrm{pH}_{\mathrm{pzc}}$ point towards lower $\mathrm{pH}$ values, i.e., to about $\mathrm{pH}$ 9.3. Adsorption of simple monovalent anions usually results in an increase in the surface charge, which is a result of creation of an additional number of positively charged surface groups with which negatively charged ions interact directly (Skwarek et al. 2014). In the case of adsorption of trivalent phosphate(V) ions, the majority of their negative charge is accumulated in the by-surface layer of the solution, which results in a decrease in the $\sigma_{0}$ value of Na-A zeolite.

In the case of the anionic PAM addition, there is an increase in the $\sigma_{0}$ value of the solid (Fig. 2a); whereas for the cationic form of polyacrylamide, there is a significant decrease in the $\sigma_{0}$ value (Fig. 2b). This is due to the abovementioned effect of creating an additional number of surface adsorption sites with the specific charge sign-adsorption of negatively charged macromolecules "forces" the creation of surface groups with a positive charge; whereas binding the positively charged polymer chains - the formation of active sites with a negative charge. The mechanism of this process can be presented by the following equations (Wiśniewska et al. 2016):

$\equiv \mathrm{Si}(\mathrm{Al})-\mathrm{OH}+\mathrm{AN} \mathrm{PAM}^{-}+\mathrm{H}^{+} \rightarrow \equiv \mathrm{Si}(\mathrm{Al})-\mathrm{OH}_{2}^{+} \mathrm{AN} \mathrm{PAM}^{-}$,

$\equiv \mathrm{Si}(\mathrm{Al})-\mathrm{OH}+\mathrm{CT} \mathrm{PAM}^{+} \rightarrow \equiv \mathrm{Si}(\mathrm{Al})-\mathrm{O}^{-} \mathrm{CT} \mathrm{PAM}^{+}+\mathrm{H}^{+}$.

$\mathrm{The} \equiv \mathrm{Si}(\mathrm{Al})-\mathrm{OH}$ represents the solid surface groups.

In the mixed adsorbate systems containing ionic polyacrylamide and phosphate $(\mathrm{V})$ ions, the largest difference in the surface charge density in comparison to the aqueous suspension of zeolite was obtained. In such a situation, complexes between the polymer macromolecules and inorganic ions are formed. As a result, the conformation of adsorbing polymer chains was changed leading to the specific structure of the surface adsorption layer. The mechanism of these complexes creation can have electrostatic nature (interactions of positively charged CT PAM functional groups with phosphate $(\mathrm{V})$ anions) or the hydrogen bonds between the neutral PAM amide groups and phosphate $(\mathrm{V})$ ions (particularly important in the case of anionic polyacrylamide) can be formed.

The ionic composition of the surface layer, which affects the sign and density of the surface charge, may differ significantly from that of the slipping plane area which is part of electrical double layer (edl) and is located at a certain distance from the solid surface. The parameter that refers to the slipping plane area is the zeta $(\zeta)$ potential. Figure 3 shows the changes in the $\zeta$ potential values as a function of the solution $\mathrm{pH}$ for the $\mathrm{Na}-\mathrm{A}$ samples dispersed in water and aqueous solutions of AN PAM, CT PAM, phosphate(V) ions, as well as mixed solutions of both adsorbates, i.e., AN $\mathrm{PAM}+$ phosphate $(\mathrm{V})$ ions and CT PAM + phosphate $(\mathrm{V})$ ions. The isoelectric point (iep) for aluminosilicate without adsorbates occurs at $\mathrm{pH}$ of about 5 and is significantly different from the $\mathrm{pH}_{\mathrm{pzc}}$ point which is about 10. At $\mathrm{pH}$ equal to $\mathrm{pH}_{\text {iep }}$, the charge accumulated in the slipping plane area is zero which indicates that the concentrations of negatively and positively charged functional groups and ions are the same.

In the presence of phosphate $(\mathrm{V})$ ions in the aqueous zeolite suspension, there is a clear increase of the absolute values of zeta potential of solid particles in the whole range of studied $\mathrm{pH}$ (compared to the system without the polymer). On the other hand, the addition of ionic PAM results in a rapid increase in the absolute values of $\zeta$ potential value (Fig. 3). In the case of CT PAM, the $\zeta$ potential value reaches even $60 \mathrm{mV}$. This is primarily due to the presence of the adsorbate molecules containing functional groups with electric charge which are located in the area of the slipping 

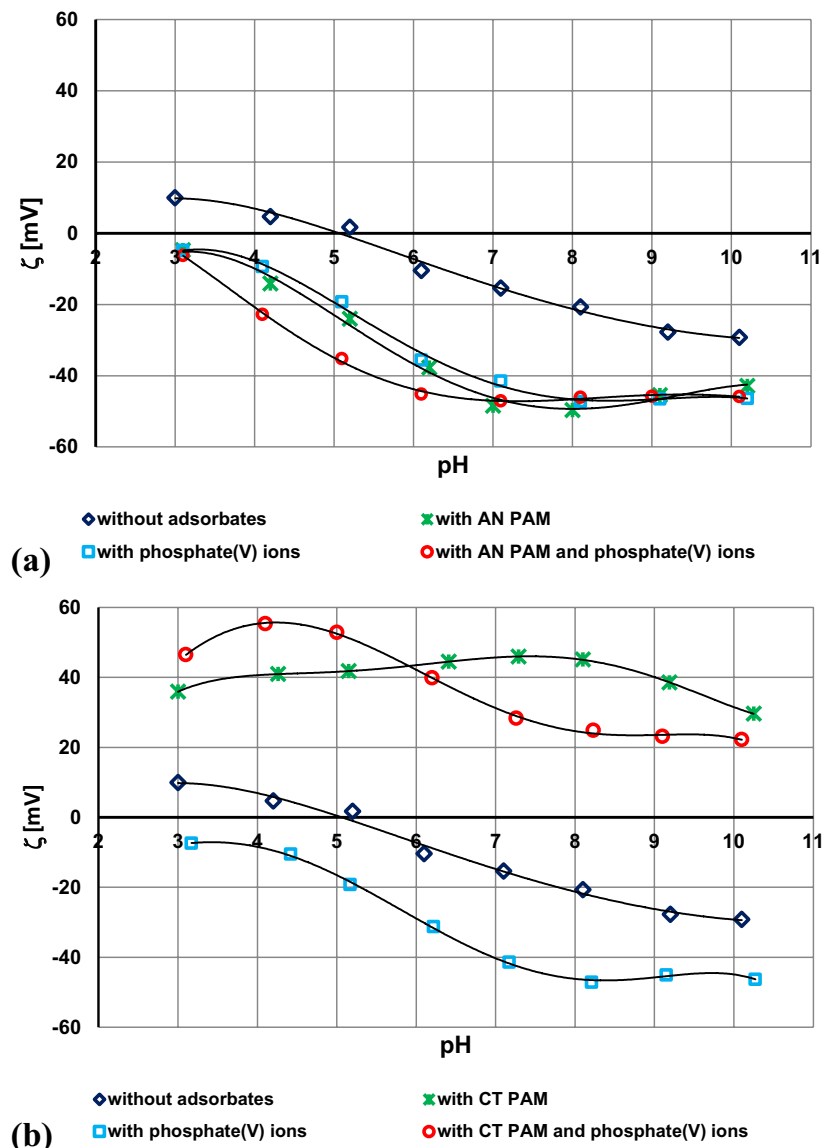

Fig. 3 Zeta potential of Na-A zeolite particles without and with adsorbed PAM or/and phosphate(V) ions: a AN PAM, b CT PAM

plane and affect the value of the electrokinetic potential. In the mixed adsorbate systems [ionic polymer + phosphate ions $(\mathrm{V})]$, the greatest changes in the zeta potential in comparison to the basic zeolite suspension were obtained (similarly to those in the surface charge density).

Changes in the zeta potential caused by adsorption of macromolecular substances and their complexes with inorganic ions are very complex and are the result of many phenomena occurring at the solid-solution interface (M'Pandou and Siffert 1987; Chibowski and Wiśniewska 2001). This is mainly shift of the slipping plane from the surface of the solid particle caused by the binding of macromolecules of significant sizes. Secondly, the presence of charged polymer functional groups and phosphate $(\mathrm{V})$ ions on the border separating the stiff part of the double electrical layer from its moving part results in a change in the ionic composition of this area. This ionic composition can be also modified as a result of "pushing out" from the surface layer of simple ions present in the zeolite surface structure by adsorbing the PAM chains and the PAM-phosphate(V) ions complexes towards the diffusion part of edl.

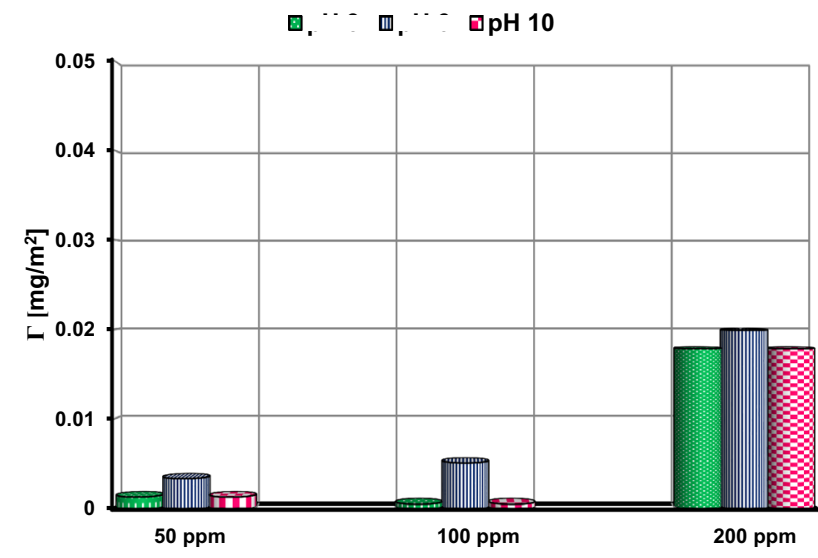

(a)

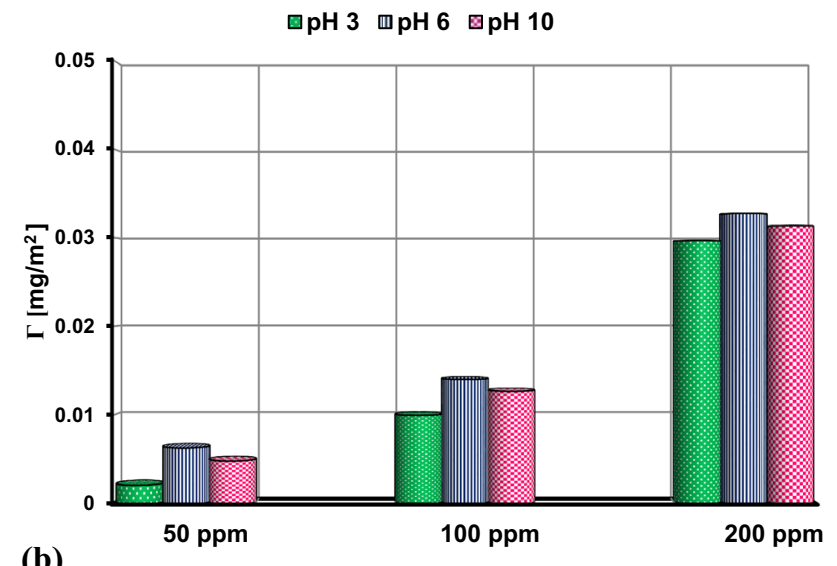

(b)

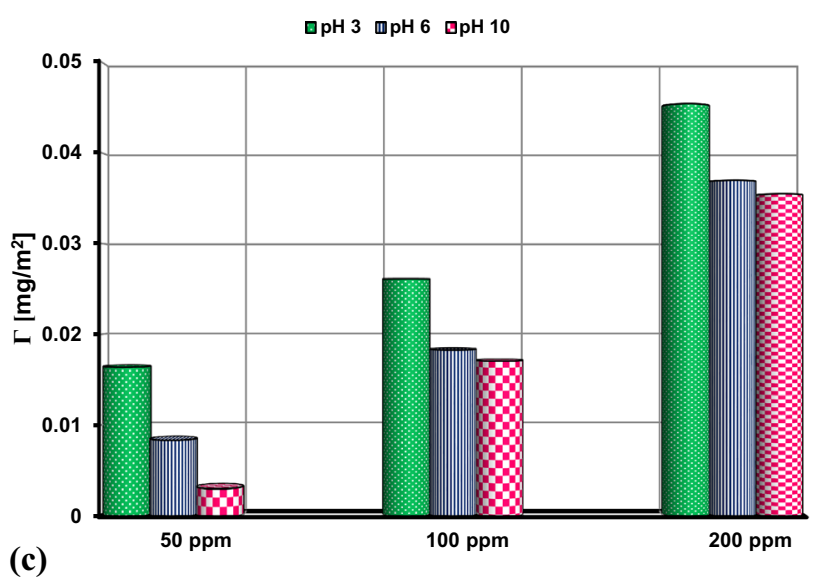

Fig. 4 Adsorbed amounts $(\Gamma)$ of adsorbates on the Na-A zeolite surface Na-A obtained in solutions at $\mathrm{pH}$ 3, 6 and 10 for initial adsorbate concentrations of 50, 100 and 200 ppm: a AN PAM, b CT PAM, c phosphate $(\mathrm{V})$ ions

The determined electrokinetic parameters (solid surface charge density and zeta potential) are extremely helpful in explaining the adsorption affinity (expressed in the adsorbed amount $\Gamma$ ) of the ionic polymer and phosphate $(\mathrm{V})$ ions on the Na-A zeolite surface in simple 
and mixed adsorbate systems. Figure 4 presents the results of adsorption measurements performed from the single adsorbate solutions (AN PAM, CT PAM and phosphate(V) ions).

For all examined initial concentrations of the polymer, both in the case of anionic and cationic forms of polyacrylamide (Fig. 4 a) and b)), their adsorption increases evidently in the $\mathrm{pH}$ range 3-6; whereas at $\mathrm{pH} 10$, a decrease of $\Gamma$ value is observed (compared to that obtained at $\mathrm{pH} 6$ ). Thus, the greatest amount of adsorbed PAM was obtained at $\mathrm{pH} 6$, regardless of its ionic character, which seems to be very surprising. Moreover, the cationic polyacrylamide is adsorbed more efficiently on the zeolite surface than the anionic polyacrylamide. Both polymers show practically $100 \%$ dissociation of their functional groups at $\mathrm{pH} 6$ and for this reason, the conformation of their macromolecules is more developed (the electrostatic repulsion of the same charges accumulated along the polymeric chains). Therefore, the mechanism of interactions of AN PAM macromolecules with a positively charged zeolite surface at pH 6 is, therefore, electrostatic attraction. On the other hand, in the case of CT PAM, polymer binding takes place probably by exchanging inorganic cations present in the zeolite surface structure with the polymer cationic groups. This is so effective that it provides a greater amount of adsorbed CT PAM compared to AN PAM. Additionally, the PAM molecular weight has some influence on the polymeric chain conformation on the solid surface. Due to electrostatic attraction of totally dissociated AN PAM with positively charged solid surface at $\mathrm{pH} 6$, the conformation of adsorbed macromolecules is rather flat. This caused the blockade of solid surface and its unavailability for other molecules. AN PAM is characterized by above two times higher molecular weight $(15,500,000 \mathrm{Da})$ in comparison to CT PAM (7,000,000 Da); thus, this effect is significant (the AN PAM adsorbed amount at $\mathrm{pH} 6$ reaches level of about $0.02 \mathrm{mg} / \mathrm{m}^{2}$ ). On the other hand, the conformation of adsorbed CT PAM macromolecules is more developed towards the bulk solution (due to electrostatic repulsion between adsorbent and adsorbate—both positively charged). As a result, the higher adsorption is obtained (the CT PAM adsorbed amount at $\mathrm{pH} 6$ reaches level of about $0.033 \mathrm{mg} /$ $\mathrm{m}^{2}$ ).

Partial dissociation of the polyacrylamide ionic groups occurs at $\mathrm{pH} 3$ for its anionic form and at $\mathrm{pH} 10$ for its cationic form (Table 1). This results in a lower degree of development of adsorbing polymer chains and lower adsorption affinity of AN PAM at $\mathrm{pH} 3$ and CT PAM at pH 10 (compared to the adsorbed amounts obtained at $\mathrm{pH} 6$ ).

The SEM images of Na-A zeolite particles without and with ionic polyacrylamides are presented in Fig. 5. All samples were prepared at $\mathrm{pH}$ 6. As can be seen, the CT PAM shows high aggregation ability in relation to solid (a)

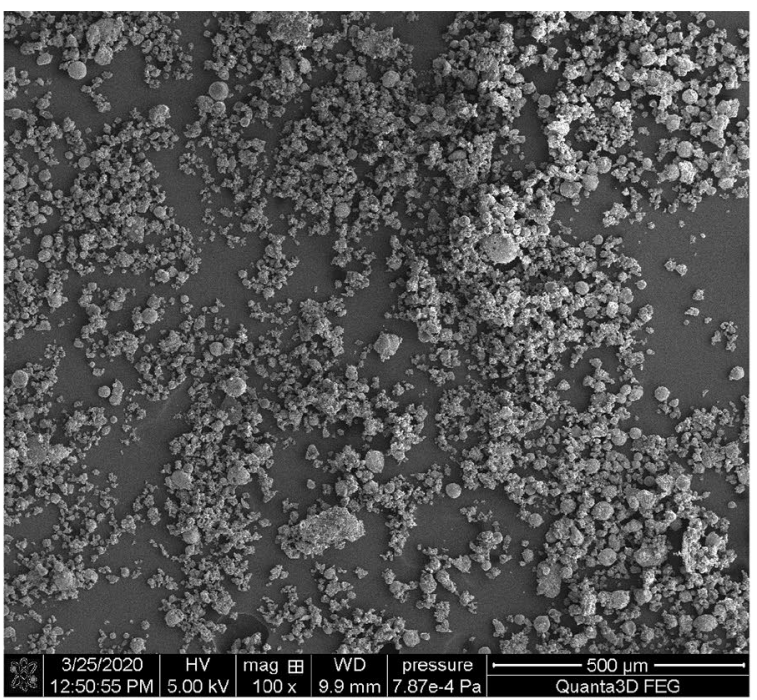

(b)

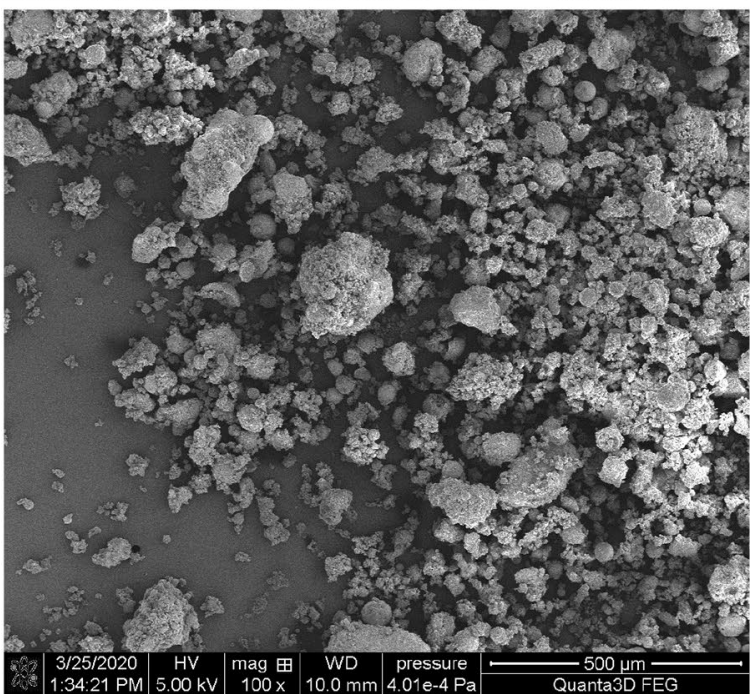

(c)

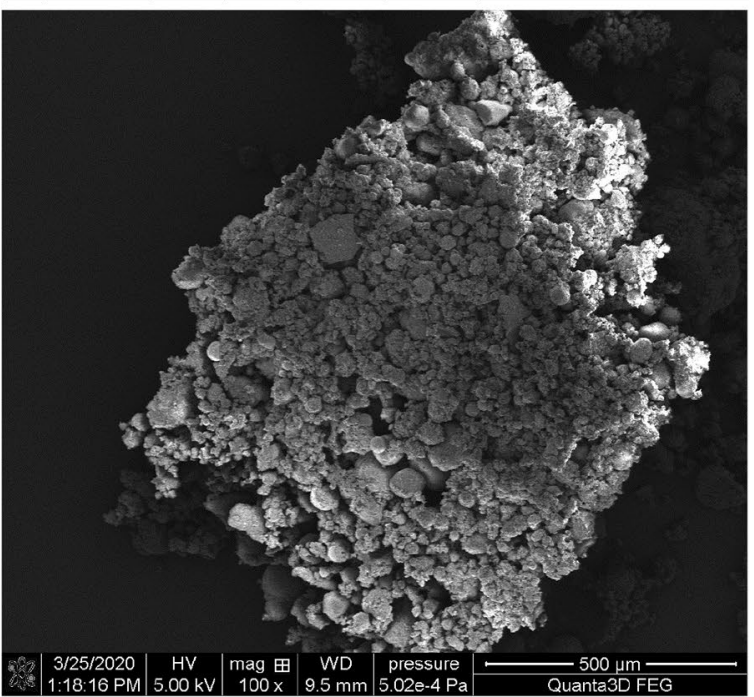

Fig.5 SEM images of Na-A zeolite particles: a without PAM, $\mathbf{b}$ with AN PAM, $\mathbf{c}$ with CT PAM 
particles (Fig. 5c). As was mentioned above, its adsorption layer is characterized by significant development of PAM chains towards the liquid phase and for this reason the creation of polymer bridges is greatly privileged (flocks with large sizes are formed). In the presence of AN PAM small aggregates are formed at $\mathrm{pH} 6$ (Fig. 5b). The mechanism of slight destabilization of the zeolite suspension in such a system is associated with the solid positive surface charge neutralization by flat adsorbed chains endowed with negative charge.

A completely different tendency was observed for phosphate $(\mathrm{V})$ ions undergoing adsorption on the surface of Na-A zeolite in the solutions of different $\mathrm{pH}$ values (Fig. 4c). For all examined concentrations of these ions, a clear decrease in the adsorbed amount was obtained with the increasing solution $\mathrm{pH}$. This is caused by the decrease of the density of the zeolite positive surface charge in the $\mathrm{pH}$ range 3-10 and, thus, the reduction of electrostatic attraction between the solid surface and inorganic anions. Moreover, in the case of phosphate( $\mathrm{V}$ ) ions, a significantly higher level of their adsorption at the aluminosilicate-solution interface was obtained than in the presence of the polymer. This is probably due to the penetration of these ions into the zeolite mesopores with an average size of approx. $7.3 \mathrm{~nm}$ which is impossible in the case of large polyacrylamide macromolecules (Wiśniewska et al. 2014, 2015).

The results of adsorption measurements performed in the $\mathrm{pH}$ 3-10 range in the systems containing mixed adsorbates are presented in Fig. 6 [for AN PAM + phosphate(V) ions] and in Fig. 7 [for CT PAM + phosphate(V) ions]

The zeolite composites prepared with the use of anionic polymers have a different effect on the "capture" of phosphate(V) ions from an aqueous solution depending on the solution pH (Fig. 5). The AN PAM-modified zeolite systems prepared at $\mathrm{pH} 3$ adsorbed inorganic ions less effectively compared to the solid unmodified with the anionic polymer. On the other hand, at $\mathrm{pH} 6$ the modification did not have a significant impact on the amount of bound inorganic ions, whereas at $\mathrm{pH} 10$ the adsorbed amount of these ions clearly increased. In the case of AN PAM-zeolite composites, their effectiveness in removal of phosphate $(\mathrm{V})$ ions from aqueous solutions results from the structure of the polymer adsorption layer. On one hand this determines the access of small inorganic ions to the solid pores; and on the other hand, their access to the amide groups of adsorbed macromolecules [formation of hydrogen bonds (Bajpai 2007)].

The increase in the amount of adsorbed phosphate $(\mathrm{V})$ ions on the zeolite surface covered with the cationic polyacrylamide layer is due primarily to the capture of these ions by the positively charged amine groups of CT PAM
口AN PAM mphosphate(V) ions $\square$ AN PAM + phosphate(V) ions

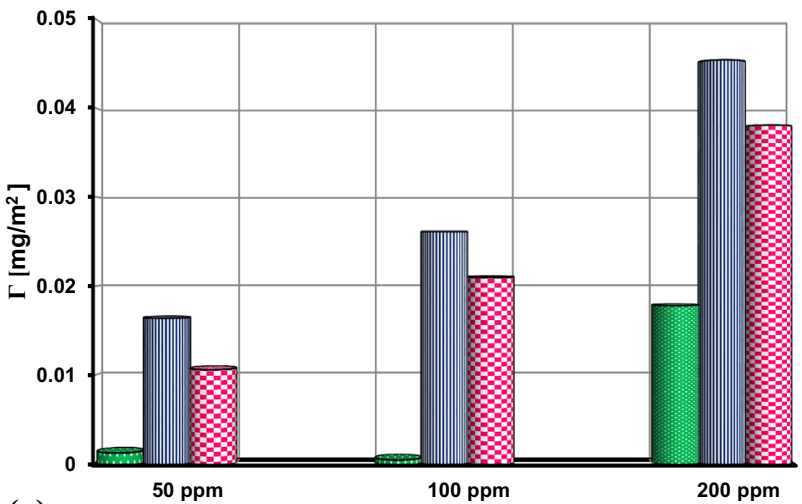

(a)

口AN PAM mphosphate(V) ions 巴AN PAM + phosphate(V) ions

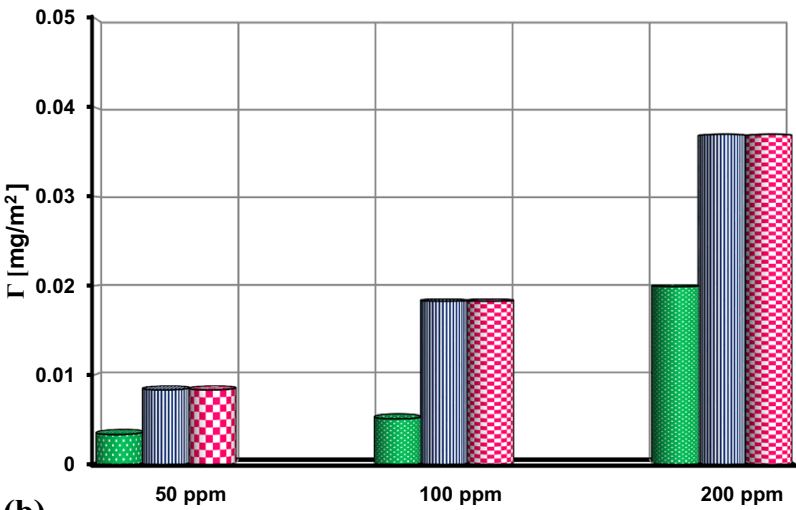

(b)

口AN PAM mphosphate(V) ions $\square$ AN PAM + phosphate(V) ions

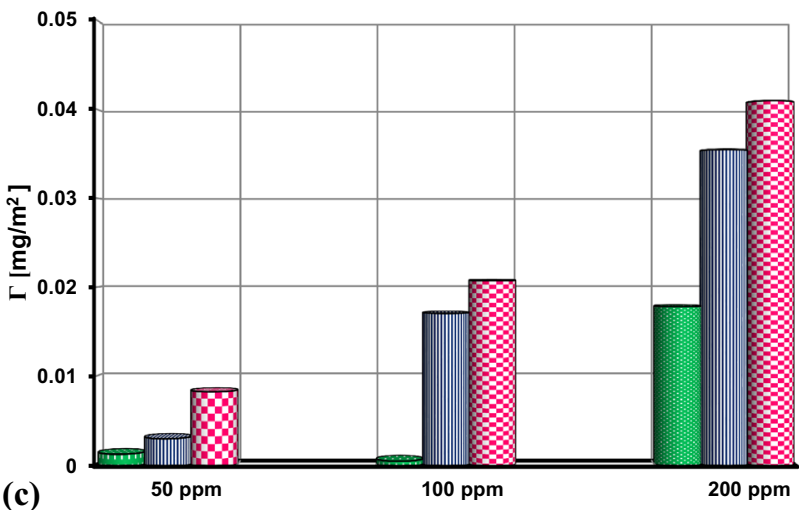

Fig. 6 Adsorbed amounts $(\Gamma)$ of phosphate(V) ions on the surface Na-A zeolite previously covered with AN PAM layer (with an initial concentration of $100 \mathrm{ppm}$ ) for initial concentrations of inorganic ions of 50, 100 and 200 ppm obtained at: $\mathbf{a}$ pH 3, b pH 6, c pH 10

(Fig. 6). The conformation of adsorbed macromolecules is also important, because it affects the thickness and packing degree of the polymeric surface layer. It influences the availability of the inner surface of zeolites, i.e., the possibility of 
圆CT PAM mphosphate(V) ions ECT PAM + phosphate(V) ions

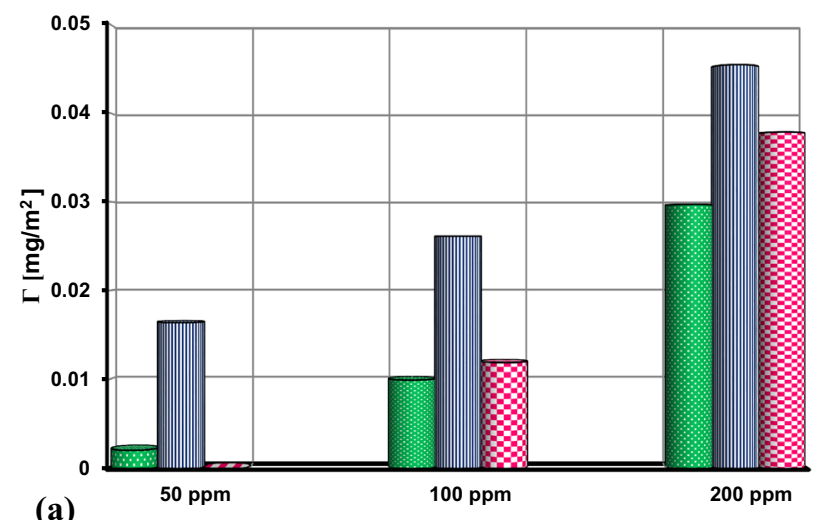

(a)

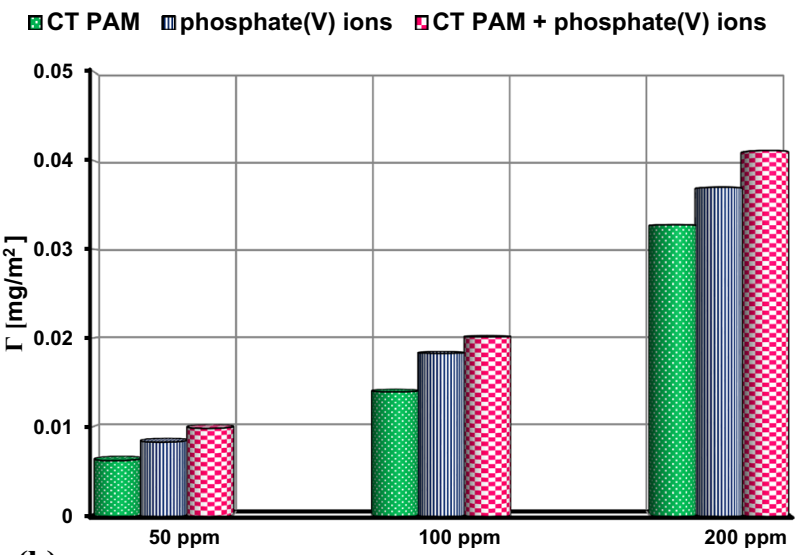

(b)
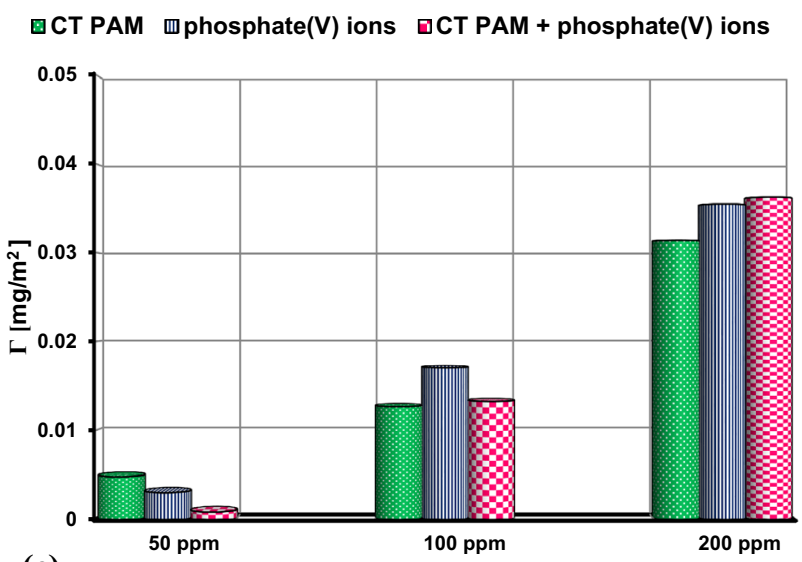

(c)

Fig. 7 Adsorbed amounts $(\Gamma)$ of phosphate(V) ions on the surface Na-A zeolite previously covered with CT PAM layer (with an initial concentration of $100 \mathrm{ppm}$ ) for initial concentrations of inorganic ions of 50, 100 and 200 ppm obtained at: a pH 3, b pH 6, c pH 10 penetration into the pores of "small" inorganic ions-the adsorbed polymer chains with a specific structure can block the entry of solid pores (Fig. 7).

The desorption tests (Table 2) indicated that in the case of AN PAM its removal from the solid surface is caused by $\mathrm{HCl}$ more effectively (74\%) than by $\mathrm{NaOH}(57 \%)$. This proved that small $\mathrm{Cl}^{-}$anions were preferably bounded with the zeolite surface in comparison to carboxyl groups of AN PAM. Similarly, in the case of CT PAM the sodium chloride desorbed cationic polymer macromolecules in large quantities (89\%). In turn, the effective desorption (79\%) of the phosphate(V) ions was caused by $\mathrm{NaOH}$. In the mixed adsorbate systems, the presence of ionic polyacrylamide adsorption layers favored the desorption of phosphate(V) ions-in all examined systems, it reaches levels above $90 \%$.

\section{Conclusions}

The obtained results show that the synthetic zeolite $\mathrm{Na}-\mathrm{A}$ (obtained from the waste material such as fly ash) can be useful in the process of removing phosphate( $\mathrm{V})$ ions from aqueous solutions. The modification of its surface by adsorption of ionic polyacrylamide carried out under different $\mathrm{pH}$ conditions causes a change in the electrokinetic properties of the system which affects the efficiency of phosphate(V) ions binding by this synthetic aluminosilicate. In the whole examined $\mathrm{pH}$ range, there are favorable electrostatic conditions for adsorption of the anionic PAM and phosphate( $\mathrm{V})$ ions on the positively charged surface of the zeolite. In the case of the cationic PAM adsorption on the aluminosilicate surface, the exchange of simple cations present in the surface structure of zeolite with a positively charged polymer amino group probably takes place. Modification of the synthetic zeolite Na-A with an ionic polyacrylamide results in change in the adsorption affinity of the formed composite in relation to the phosphate $(\mathrm{V})$ ions. The Na-A/ionic PAM composites prepared under specific pH conditions (particularly at $\mathrm{pH} 10$ ) exhibit better sorption capacity with respect to phosphate( $\mathrm{V})$ ions compared to the unmodified zeolite. In the mixed adsorbate systems, the presence of ionic polyacrylamide favors the significant desorption (above 90\%) of phosphate( $\mathrm{V}$ ) ions by the use of $\mathrm{HCl}$ and $\mathrm{NaOH}$. 
Table 2 Desorption [\%] of AN PAM, CT PAM and phosphate(V) ions from Na-A zeolite surface in the simple and mixed systems of adsorbates at $\mathrm{pH} 6$; concentration of desorbing agents was $0.05 \mathrm{~mol} /$ $\mathrm{dm}^{3}$

\begin{tabular}{llll}
\hline Desorbing agent & Desorption [\%] & & \\
\hline & AN PAM & AN PAM + phosphate(V) ions & \\
& & AN PAM & Phosphate(V) ions \\
$\mathrm{HCl}$ & 74 & 57 & 91 \\
$\mathrm{NaOH}$ & 57 & 30 & 99 \\
& Phosphate(V) ions & & \\
$\mathrm{HCl}$ & 15 & & \\
$\mathrm{NaOH}$ & 79 & CT PAM+phosphate(V) ions & \\
& CT PAM & CT PAM & Phosphate(V) ions \\
& 89 & 5 & 93 \\
$\mathrm{HCl}$ & 6 & 0 & 100 \\
$\mathrm{NaOH}$ & & & \\
\hline
\end{tabular}

Funding This work was financed by the National Centre for Research and Development project Lider contract number LIDER/19/0072/L-9/17/NCBR/2018.

\section{Compliance with ethical standards}

Conflict of interest On behalf of all authors, I state that there is no conflict of interest.

Open Access This article is licensed under a Creative Commons Attribution 4.0 International License, which permits use, sharing, adaptation, distribution and reproduction in any medium or format, as long as you give appropriate credit to the original author(s) and the source, provide a link to the Creative Commons licence, and indicate if changes were made. The images or other third party material in this article are included in the article's Creative Commons licence, unless indicated otherwise in a credit line to the material. If material is not included in the article's Creative Commons licence and your intended use is not permitted by statutory regulation or exceeds the permitted use, you will need to obtain permission directly from the copyright holder. To view a copy of this licence, visit http://creativecommons.org/licenses/by/4.0/.

\section{References}

Abu-Zied BM (2011) $\mathrm{Cu}^{2+}$ acetate exchanged X zeolites: Preparation, characterization and $\mathrm{N}_{2} \mathrm{O}$ decomposition activity. Micropor Mesopor Mater 139:59-66

Al-Zboon KK (2018) Phosphate removal by activated carbon-silica nanoparticles composite, kaolin, and olive cake. Env Dev Sustain 20:2707

Bajpai SK, Johnson S (2007) Removal of Cr (VI) Oxy-anions from aqueous solution by sorption into poly(acrylamide-co-maleic acid) hydrogels. Sep Purif Tech 42:1049-1064

Bandura L, Kołodyńska D, Franus W (2017) Adsorption of BTX from aqueous solutions by Na-P1 zeolite obtained from fly ash. Process Saf Env Prot 109:214-223

Bandura L, Panek R, Rotko M, Franus W (2016) Synthetic zeolites from fly ash for an effective trapping of BTX in gas stream. Microporous Mesoporous Mater 223:1-9

Bashan LE, Hernandez JP, Morey T, Bashan Y (2004) Microalgae growth-promoting bacteria as "helpers" for microalgae: a novel approach for removing ammonium and phosphorus from municipal wastewater. Water Res 38:466-474
Bazan-Woźniak A, Nowicki P, Pietrzak R (2017) The influence of activation procedure on the physicochemical and sorption properties of activated carbons prepared from pistachio nutshells for removal of $\mathrm{NO}_{2} / \mathrm{H}_{2} \mathrm{~S}$ gases and dyes. J Clean Prod 152:211-222

Bouzid J, Elouear Z, Feki M, Jamoussi F, Montiel A (2008) Phosphorus removal from aqueous solution using iron coated natural and engineered sorbents. J Hazard Mat 151:103-110

Bukhari SS, Behin J, Kazemian H, Rohani S (2015) Conversion of coal fly ash to zeolite utilizing microwave and ultrasound energies: a review. Fuel 140:250-266

Chibowski S, Wiśniewska M (2001) Study of the adsorption mechanism and the structure of adsorbed layers of polyelectrolyte at metal oxide-solution interface. Adsorpt Sci Tech 19:409-421

Crummett WB, Hummel RA (1963) The determination of traces of polyacrylamides in water. J Am Water Works Assoc 1:209-219

Cygański A (1999) Fundamentals of electroanalytical methods. Scientific Technical Publishing House, Warsaw

Franus W, Wdowin M, Franus M (2014) Synthesis and characterization of zeolites prepared from industrial fly ash. Environ Monit Assess 186:5721-5729

Goncharuk O, Shipul O, Dyachenko A, Ischenko O, Andriyko L, Marynin A, Pakhlov E, Oranska O, Borysenko M (2019) Silica-supported $\mathrm{Ni}$ and Co nanooxides: colloidal properties and interactions with polar and nonpolar liquids. J Mol Liq 285:397-402

Holan ZR, Volesky B (1994) Biosorption of lead and nickel by biomass of marine algae. Biotech Bioeng 43:1001-1009

Hunter RJ (1981) Zeta potential in colloid science. Academic Press, New York, p 1981

Janusz W (1994) Electrical double layer at the metal oxide/electrolyte interface in interfacial forces and fields: theory and applications. In: Decker M (ed) Surfactant Science, vol. 85, chapter 4, New York

Jiang Ch, Jia L, He Y, Zhang B, Kirumba G, Xie J (2013) Adsorptive removal of phosphorus from aqueous solution using sponge iron and zeolite. J Colloid Interf Sci 402:246-252

Li M, Wu YJ, Yu ZL, Sheng GP, Yu HQ (2009) Enhanced nitrogen and phosphorus removal from eutrophic lake water by Ipomoea aquatica with low-energy ion implantation. Water Res 43:1247-1256

Liu H, Sun X, Yin Ch, Hu Ch (2008) Removal of phosphate by mesoporous $\mathrm{ZrO}_{2}$. J Hazard Mat 151:616-622

M'Pandou A, Siffert B (1987) Polyethyleneglycol adsorption at the $\mathrm{TiO}_{2}-\mathrm{H}_{2} \mathrm{O}$ interface-distortion of ionic structure and shear plane position. Colloids Surf A 24:159-172

Minczewski J, Marczenko Z (1985) Analytical chemistry. National Scientific Publishing House, Warsaw 
Ng EP, Delmotte L, Mintova S (2009) Selective capture of water using microporous adsorbents to increase the lifetime of lubricants. Chemsuschem 2:255-260

Scoggins MW, Miller JW (1975) Spectrophotometric determination of water soluble organic amides. Anal Chem 47:152-154

Selman M, Greenhalgh S (2010) Eutrophication: sources and drivers of nutrient pollution. Renew Res J 26:19-26

Skwarek E, Janusz W, Sternik D (2014) Adsorption of citrate ions on hydroxyapatite synthetized by various methods. J Radioanal Nucl Chem 299:2027-2036

Wachowski L, Kirszensztejn P (1999) Exercises in fundamentals of environmental chemistry. Adam Mickiewicz University in Poznań, Poznań

Wawrzkiewicz M, Wiśniewska M, Gunko VM, Zarko VI (2015) Adsorptive removal of acid, reactive and direct dyes from aqueous solutions and wastewater using mixed silica-alumina oxide. Powder Tech 278:306-315

Wdowin M, Franus M, Panek R, Bandura L, Franus W (2014) The conversion technology of fly ash into zeolites. Clean Tech Env Policy 16:1217-1223

Wiśniewska M (2018) Polyacrylamide (PAM). In: High performance polymers and their nanocomposites. Chapter 1.3, Wiley, New York

Wiśniewska M, Chibowski S, Urban T (2014) Effect of the presence of cationic polyacrylamide on the surface properties of aqueous alumina suspension-stability mechanism. Appl Surf Sci 320:843-851

Wiśniewska M, Chibowski S, Urban T (2015) Impact of polyacrylamide with different contents of carboxyl groups on the chromium (III) oxide adsorption properties in aqueous solution. J Hazard Mat 283:815-823

Wiśniewska M, Fijałkowska G, Nosal-Wiercińska A, Franus M, Panek R (2019) Adsorption mechanism of poly(vinyl alcohol) on the surfaces of synthetic zeolites: sodalite, Na-P1 and Na-A. Adsorption 25:567-574

Wiśniewska M, Nowicki P, Bogatyrov VM, Nosal-Wiercińska A, Pietrzak R (2016) Comparison of adsorption properties of $\mathrm{Mg}_{\mathrm{x}} \mathrm{O}_{\mathrm{y}}-\mathrm{SiO}_{2}$ and $\mathrm{Zn}_{\mathrm{x}} \mathrm{O}_{\mathrm{y}}-\mathrm{SiO}_{2}$ in the mixed oxide-poly(vinyl alcohol) system. Colloids Surf A 492:12-18

Wiśniewska M, Nowicki P, Nosal-Wiercińska A, Pietrzak R, Szewczuk-Karpisz K, Ostolska I, Sternik D (2017) Adsorption of poly(acrylic acid) on the surface of microporous activated carbon obtained from cherry stones. Colloids Surf A 514:137-145

Yang K, Li Z, Zhang H, Chen G (2010) Municipal wastewater phosphorus removal by coagulation. Environ Tech 31:601-609

Yang X, Wu X, Hao H, He Z (2008) Mechanisms and assessment of water eutrophication. J Zhejiang Univ Sci B 9:197-209

Zainal Abidin A, Abu Bakar NHH, Ng EP, Tan WL (2017) Rapid degradation of methyl orange by $\mathrm{Ag}$ doped zeolite $\mathrm{X}$ in the presence of borohydride. J Taibah Univ Sci 11:1070-1079

Publisher's Note Springer Nature remains neutral with regard to jurisdictional claims in published maps and institutional affiliations. 